\title{
Bioinspired Mechanically Adaptive Polymer Nanocomposites with Water-Activated Shape-Memory Effect
}

\author{
Julie Mendez, ${ }^{+, \#}$ Pratheep K. Annamalai, ${ }^{+}$Stephen J. Eichhorn, ${ }^{\ddagger}$ Rafeadah Rusli, ${ }^{\ddagger}, \perp$ Stuart J. Rowan, ${ }^{\S}$ \\ E. Johan Foster, ${ }^{*,+}$ and Christoph Weder, ${ }^{*,+}$ \\ ${ }^{\dagger}$ Adolphe Merkle Institute and Fribourg Center for Nanomaterials, University of Fribourg, Rte de l'Ancienne Papeterie, \\ P.O. Box 209, 1723 Marly, Switzerland \\ ${ }^{\ddagger}$ Materials Science Centre and the Northwest Composites Centre, School of Materials, Paper Science Building, \\ University of Manchester, Sackville Street, Manchester, M13 9PL, U.K. \\ ${ }^{\S}$ Department of Macromolecular Science and Engineering, Case Western Reserve University, 2100 Adelbert Road, Cleveland, \\ Ohio 44106-7202, United States
}

\begin{abstract}
New biomimetic, stimuli-responsive mechanically adaptive nanocomposites, which change their mechanical properties upon exposure to water and display a water-activated shape-memory effect, were investigated. These materials were produced by introducing rigid cotton cellulose nanowhiskers (CNWs) into a rubbery polyurethane (PU) matrix. A series of materials with CNW concentrations of $2-20 \%$ v/v was produced by solution blending CNWs and the PU. Films were subsequently prepared by compression molding. The introduc-
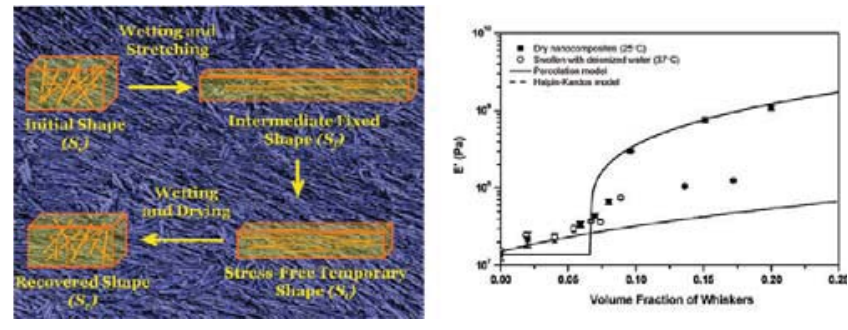
tion of CNWs led to an increase of the tensile storage moduli $\left(E^{\prime}\right)$ in the dry nanocomposites. The level of reinforcement scaled with the CNW content and followed the Halpin-Kardos model below and the percolation model above the percolation limit of $\sim 7 \%$ $\mathrm{v} / \mathrm{v}$. Upon exposure to water, the materials with a CNW content above the percolation limit swelled slightly and showed a decrease of $E^{\prime}$, for example from $1 \mathrm{GPa}$ to $144 \mathrm{MPa}$ in the case of the material with $20 \% \mathrm{v} / \mathrm{v}$ CNWs. This effect is the result of competitive hydrogen bonding between water and CNWs, which reduces the hydrogen bonding between the CNWs and weakens the CNW network that drives the reinforcement in the dry state. The mechanically adaptive behavior and a high elasticity of the wet materials are the basis for a shapememory effect that uses water as the stimulus. Polarized Raman spectroscopy revealed that in the temporary shape, generated by stretching and drying water-swollen nanocomposites, the CNWs display a significant level of uniaxial orientation.
\end{abstract}

\section{INTRODUCTION}

Materials ${ }^{1-4}$ that can be manipulated to a "fixed" temporary shape and reverted later to the "memorized" original shape upon exposure to an external stimulus such as heat, ${ }^{1-3}$ light, ${ }^{5-7}$ magnetic fields, ${ }^{8,9}$ or chemicals ${ }^{10-13}$ are useful for a plethora of potential applications that range from mechanically adaptive materials for biomedical devices ${ }^{2,14-18}$ to aerospace structures ${ }^{18,19}$ to dry adhesives ${ }^{20}$ to optical devices. ${ }^{21}$ Polymers intrinsically show shapememory effects, on the basis of rubber elasticity, but with varied characteristics of strain recovery rate, work capability during recovery, and retracted state stability. The elasticity can be imparted by covalent or physical cross-links. The polymer is typically deformed in its rubbery state above a transition temperature $\left(T_{\text {trans }}\right)$, i.e., either glass transition, crystallization, or melting temperature, is cooled to below the transition temperature $\left(T_{\text {trans }}\right)$ to fix a temporary shape in which the energy used for deformation is stored. Later, the recovery to its original shape is driven by regaining the entropy lost during deformation. ${ }^{22}$ The ability to fix temporary shapes depends mainly on the possibility to create discrete reversible phase transitions in the polymer. $^{23-26}$ Thus, a broad range of different shape-memory polymers has been or can be developed, which exploit various reversible phase transitions and are designed to respond to different external stimuli. The most widely studied behavior is a purely thermally induced shape-memory effect, which relies on heating to above and cooling to below a transition temperature; indirect heating upon exposure of appropriately modified systems to an electrical current, magnetic field, or light represent interesting variations of this approach. ${ }^{27-30}$ A light-induced shape-memory effect was also demonstrated, which was achieved by introducing photoresponsive cinnamic acid units into acrylate hydrogels. This allows one to trigger the shape-memory effect with light under isothermal conditions. ${ }^{5}$ Comparably few materials have been described in which the shape-memory recovery can be triggered by a chemical stimulus. One design approach for such materials relies on the reduction of the glass transition temperature $\left(T_{\mathrm{g}}\right)$ of thermoresponsive shape-memory polyurethanes by way of plasticization upon immersion in water; here, the fixation of the temporary shape involved deformation at elevated temperature and cooling below $T_{\mathrm{g}}{ }^{10,11,31}$ Recently a purely solvent-induced shape-memory effect was also reported for a chemically cross-linked polyvinyl alcohol. ${ }^{12,13}$ 


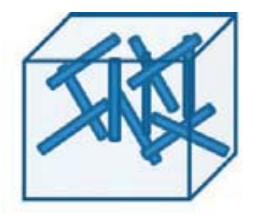

Initial shape $\left(S_{1}\right)$

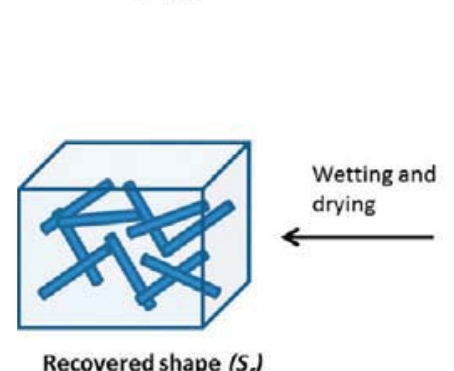

Recovered shape (S)

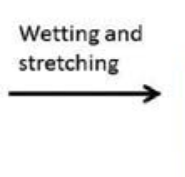

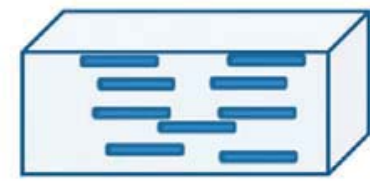

Intermediate fixed shape $\left(S_{f}\right)$

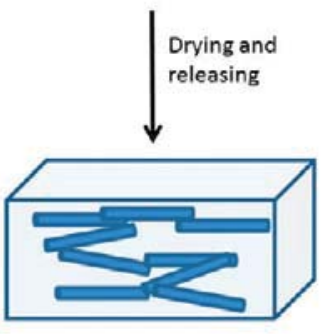

Stress-free temporary shape $\left(S_{t}\right)$
Figure 1. Schematic representation of the shape-memory materials explored here, which rely on switching the interactions between cellulose nanowhiskers within a polymer matrix upon addition and removal of water.

We here report the development of a new type of shapememory material, in which the temporary shape is fixated and released by the formation and disassembly of a network of rigid nanofibers upon removal of and exposure to water, respectively. The design is an evolution of the chemically responsive, mechanically dynamic polymer nanocomposites we have previously reported. ${ }^{32-39}$ These materials are inspired by the function and architecture of the sea cucumber dermis ${ }^{40,41}$ and rely on the incorporation of rigid cellulose nanofibers (also referred to as cellulose nanowhiskers) into a low-modulus polymer matrix that accommodates moderate aqueous swelling. Cellulose nanowhiskers, which can be isolated from a variety of biosources, are particularly attractive for this purpose, as they offer high stiffness (tensile modulus $\sim 100-130 \mathrm{GPa})$ and aspect ratio $(\sim 25 \mathrm{~nm} \times$ $0.2-2 \mu \mathrm{m}$, depending on the source) and a surface chemistry (an abundance of hydroxyl groups) that is ideal for water-induced switching. ${ }^{32,42-45}$ Polymer nanocomposites with a percolating network of nanowhiskers can be easily fabricated by mixing nanowhiskers and polymer in a hydrogen-bond-forming solvent in which nanowhisker self-interactions through hydrogen bonding of surface hydroxyl groups are "switched off" by competitive hydrogen bonding with the solvent. ${ }^{46-49}$ Upon solvent evaporation, the interactions between the nanowhiskers are "switched on" and they assemble into a percolating network. This architecture and strong interactions between the nanowhiskers maximize stress transfer and therewith the overall modulus. The stiffness of such nanocomposites can be altered by the addition or removal of water which acts as a chemical regulator or stimuli and changes the hydrogen bonding between the nanowhiskers within the polymer matrix as shown in Figure $1 .^{32-36}$ Indeed, the uptake of a small amount of water causes a dramatic reduction in the stiffness of the materials and the original stiffness is restored when the composite is dried. ${ }^{47}$

Reporting nanocomposites based on a rubbery polyurethane matrix and cellulose nanowhiskers isolated from cotton, we show here that the combination of the above-described approach to water-triggered mechanically adaptive behavior with a highly elastic polymer matrix is the basis for a shape-memory effect that uses water as a stimulus. While the reinforcement of polyurethanes with short cellulose nanowhiskers has been described before, ${ }^{50-53}$ the here-reported shape-memory is unprecedented and offers attributes that are especially attractive for biomedical applications, ${ }^{11}$ such as self-tightening sutures, self-retractable and removable stents, and porous materials with adjustable pore size.

\section{EXPERIMENTAL SECTION}

Materials. Acetone, dimethylformamide (DMF) and sulfuric acid were purchased from Sigma-Aldrich. Texin 985, a thermoplastic polyurethane (PU) based on poly(tetramethylene glycol), butanediol, and 4,4'-methylenebis(phenyl isocyanate) with a Shore A hardness of about 85, was obtained from Bayer MaterialScience. Cellulose nanowhiskers from cotton $(\mathrm{CNWs})$ were isolated using a reported protocol. ${ }^{47,54}$ The aspect ratio $(1 / \mathrm{d})$ of these CNWs, determined by TEM was $\sim 11$ and their charge density, determined by conductivity titration following the procedure reported elsewhere, ${ }^{55}$ was about $31-35 \mathrm{mmol} \cdot \mathrm{kg}^{-1}$.

Atomic Force Microscopy and Transmission Electron Microscopy. An aqueous dispersion of the CNWs $\left(0.1 \mathrm{mg} \cdot \mathrm{mL}^{-1}\right)$ was deposited on a freshly cleaved mica surface and dried at $60^{\circ} \mathrm{C}$ under vacuum for $24 \mathrm{~h}$. A JPK SPMControl Station III with a NanoWizard II stand-alone atomic force microscope (AFM) head was used to acquire images in tapping mode. All micrographs are presented in top-view with no filtering to ensure that all images were produced with the same quality. Dispersion and dimensions of the cellulose nanowhiskers were studied using transmission electron microscopy (TEM). A $10 \mu \mathrm{L}$ drop of a $0.1 \mathrm{mg} \cdot \mathrm{mL}^{-1}$ stock solution was placed on a copper grid, supported by a $3 \mathrm{~nm}$ carbon layer with a $50 \mathrm{~nm}$ layer polymer film below. The samples were dried at $60^{\circ} \mathrm{C}$ in a vacuum oven for $2 \mathrm{~h}$ and images were then taken using a transmission electron microscope CM100 (Philips Electron Optics, Zurich, Switzerland) operating at an accelerating voltage of $80 \mathrm{kV}$. CNW dimensions quoted are averages that were obtained from measurements of a total of 50-75 CNWs in five randomly selected TEM images.

Formation of Cellulose Nanowhisker Organogels. CNW organogels were prepared from aqueous dispersions using a solventexchange sol-gel process where gelation was induced through addition of a water-miscible nonsolvent (acetone) to the CNW dispersion. In a typical gelation process, $50 \mathrm{~mL}$ of the aqueous $\mathrm{CNW}$ dispersion of a concentration of $10-12 \mathrm{mg} \cdot \mathrm{mL}^{-1}$ were placed in a $250 \mathrm{~mL}$ beaker. Acetone $(100 \mathrm{~mL})$ was gently added by letting the solvent run down the walls of the beaker so as to avoid mixing and form an organic layer on top of the aqueous $\mathrm{CNW}$ dispersion. Acetone gradually replaced the water and the top organic layer was exchanged with fresh acetone $1-2$ times daily until the bottom portion had assembled into a mechanically coherent nanowhiskeracetone gel (typically 5-7 days). When solvent exchange was no longer visible (refractive index gradients at the sol/gel interface), the acetone gel was released from the glass beaker, transferred to a screw top bottle and the solvent was exchanged twice more with dry acetone. The resulting gel was finally cut into smaller rectangular pieces, which were stored in dry acetone in a tightly sealed bottle until use. The CNW content, determined by weighing a sample of acetone gel, drying in vacuum, and weighing the remaining solid, was about $7.1 \mathrm{mg}$ of CNWs per gram of gel.

Fabrication of PU/CNW Nanocomposites. The PU was dissolved in dimethylformamide (DMF) at a concentration of $35 \mathrm{mg} \cdot \mathrm{mL}^{-1}$ by stirring for 4 days. CNW acetone gels, prepared as described above, were weighed and placed at room temperature into PU solutions of various concentrations, in which they dissolved within a few minutes. These mixtures were stirred for $16 \mathrm{~h}$, before they were cast into Teflon dishes. The solvent was evaporated under ambient conditions for $72 \mathrm{~h}$ before the films were placed for $48 \mathrm{~h}$ in an oven at $60{ }^{\circ} \mathrm{C}$, and subsequently dried under vacuum at $60{ }^{\circ} \mathrm{C}$ for $45 \mathrm{~h}$ to remove any residual solvent. The dried films were compression-molded using spacers to adjust the film thickness in a Carver press at $180{ }^{\circ} \mathrm{C}$ and 3000 psi for $120 \mathrm{~s}$ to yield $200-300 \mu \mathrm{m}$ thick nanocomposite films. 

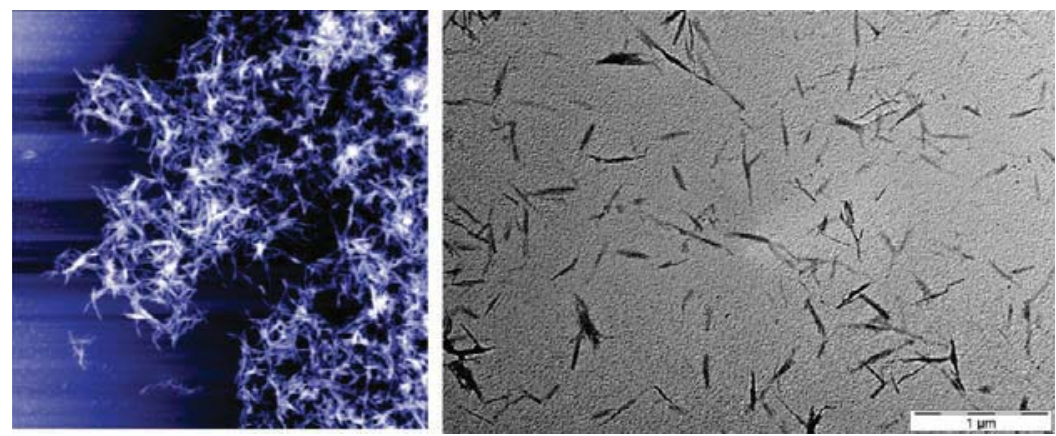

Figure 2. Left: Atomic force micro of cellulose nanowhiskers isolated from cotton on a mica surface ( $a r e a=3 \times 3 \mu \mathrm{m})$. Right: Transmission electron micrograph of cotton cellulose nanowhiskers.

Swelling Behavior. The degree of aqueous swelling of the nanocomposites was gravimetrically determined by measuring the weight of samples pre- and postswelling in deionized water at $37^{\circ} \mathrm{C}$ for 5 days:

$$
\left[\frac{\text { mass of wet sample }- \text { mass of dry sample }}{\text { mass of dry sample }}\right] \times 100
$$

To minimize the error in measuring the degree of swelling, once the wet samples were taken out of the water, they were placed on paper tissue to wick the water from the surface and the samples were then immediately weighed.

Dynamic Mechanical Thermal Analysis (DMTA). The mechanical properties of the nanocomposite films were characterized by dynamic mechanical thermal analysis (DMTA, TA Instruments Model Q800). Tests were conducted in tensile mode using a temperature sweep method $\left(23-100^{\circ} \mathrm{C}\right)$ at a fixed frequency of $1 \mathrm{~Hz}$, and a strain amplitude of $15 \mu \mathrm{m}$. All samples were dried under vacuum $(-80 \mathrm{KPa}$, $16-18 \mathrm{~h}$ ) prior to DMTA testing, unless water-swollen materials were measured. In order to determine the tensile properties of the nanocomposite films in the wet state, samples were swollen in deionized water at $37{ }^{\circ} \mathrm{C}$ for 5 days and DMTA experiments were conducted using the above setup with a submersion clamp, which allowed measurements while the samples were immersed in water. To evaluate the kinetics of softening and stiffening of the samples during wetting and drying, selected measurements were also carried out under isothermal conditions at an operating temperature of $35 \pm 2{ }^{\circ} \mathrm{C}$ upon adding or removing water. A control experiment at $37 \pm 2^{\circ} \mathrm{C}$ showed that small temperature variations did not affect the data noticeably.

Shape-Memory Behavior. A sample with an original shape $\left(S_{\mathrm{i}}\right.$ with initial length $l_{\mathrm{i}}$ ) was immersed in deionized water for 5 days, deformed to an intermediate shape $\left(S_{\mathrm{f}}\right.$ with fixed length $\left.l_{\mathrm{f}}\right)$ by stretching to a strain $\left(l_{\mathrm{f}}-l_{\mathrm{i}}\right) / l_{\mathrm{i}}=200 \%$ and drying the sample at $37{ }^{\circ} \mathrm{C}$ for $24 \mathrm{~h}$ while the length was fixed at $l_{\mathrm{f}}$. After drying, the stress was removed and the sample adopted its temporary shape $\left(S_{\mathrm{t}}\right.$ with length $\left.l_{\mathrm{t}}\right)$. The sample was subsequently immersed in deionized water at $37{ }^{\circ} \mathrm{C}$ for $24 \mathrm{~h}$ to restore the original shape; to distinguish from the original state $S_{\mathrm{i}}$ this state is referred to as recovered shape $S_{r}$ with length $l_{\mathrm{r}}$. In the case of the cyclic experiments, the sample was further dried in a vacuum oven at $37^{\circ} \mathrm{C}$ for $24 \mathrm{~h}$ to completely remove the water and rewetted for 5 days at $37^{\circ} \mathrm{C}$ for the next cycle. The expansion and contraction in the length upon wetting and drying were negligible before and after every cycle of measurements. To quantify the shape-memory effect, the shape fixing $\left(R_{\mathrm{f}}\right)$ and shape recovery $\left(R_{\mathrm{r}}\right)$, were quantified as follows: ${ }^{1}$

$$
\begin{aligned}
& R_{f}(\%)=\frac{l_{t}-l_{i}}{l_{f}-l_{i}} \times 100 \\
& R_{r}(\%)=\frac{l_{t}-l_{r}}{l_{f}-l_{i}} \times 100
\end{aligned}
$$

Here $l_{i}=$ initial length, $l_{f}=$ fixed length after deformation and drying, $l_{t}=$ length of stress-free temporary shape, and $l_{r}=$ length of the recovered specimen.

Demonstrative Object. An artificial, water-activated, self-propelled fishing lure in the shape of a worm was fabricated from a PU/ CNW nanocomposite comprising $10 \% \mathrm{v} / \mathrm{v} \mathrm{CNW}$ and $0.3 \% \mathrm{w} / \mathrm{w}$ of a colorant (Keyplast FL Red G) by manually shaping the melt. The worm was immersed in deionized water for 5 days, manually deformed to an intermediate shape, which was fixated, and the worm was dried for $24 \mathrm{~h}$ at $25{ }^{\circ} \mathrm{C}$. Relaxation was triggered by immersing the worm in deionized water at room temperature and the resulting movement was recorded using a digital camera at different time intervals during the recovery process.

Deformation Studies Using Raman Spectroscopy. A $26 \mathrm{~mW}$ (attenuated to $1 \mathrm{~mW}$ at the sample surface) $785 \mathrm{~nm}$ near-infrared laser coupled to a Renishaw System 1000 Raman spectrometer was used to record the spectra. $\mathrm{A} \times 50$ objective lens with 0.60 numerical aperture was used to focus the laser beam onto the sample to a spot size of $2 \mu \mathrm{m}$. Raman spectra were acquired in the range of 1050 to $1150 \mathrm{~cm}^{-1}$, which includes the $1095 \mathrm{~cm}^{-1}$ cellulose $\mathrm{C}-\mathrm{O}$ ring-stretching mode. ${ }^{56}$ In order to obtain spectra with minimal noise, an exposure time of $30 \mathrm{~s}$ was used. Four spectra were accumulated and averaged, giving a total exposure time of $120 \mathrm{~s}$.

Films of the PU/CNW nanocomposites with $20 \%$ v/v CNW (original sample length $\sim 20 \mathrm{~mm}$ ) were deformed after aqueous swelling to a length of between 32 and $40.5 \mathrm{~mm}$ using a customized uniaxial tensile deformation rig, kept for $5 \mathrm{~min}$, and left to relax. Raman spectra were recorded subsequent to relaxation. An unstretched nanocomposite sample and an unstretched sample of the neat PU were also measured. The polarization configuration of the laser and analyzer was such that their polarization directions were set parallel to the long axis of the samples, and therefore also to the tensile deformation axis of the specimens. The samples were rotated, using $5^{\circ}$ increments, on a customized rotation stage, and spectra were recorded at each angle increment. The recorded Raman spectra were subsequently fitted using a mixed Gaussian/Lorentzian function, and an algorithm based on the work of Marquardt ${ }^{57}$ to determine the intensity of the peak located at $1095 \mathrm{~cm}^{-1}$ as a function of rotation angle

\section{RESULTS AND DISCUSSION}

Preparation of PU/CNW Nanocomposites. Acid hydrolysis of Whatman filter paper yielded CNWs with an average width of $18 \mathrm{~nm}$, length of $200 \mathrm{~nm}$, and aspect ratio of $\sim 11$, as established by analysis of TEM images. Figure 2 shows atomic force and transmission electron micrographs of the CNWs employed. The hydrolysis protocol employed introduces a small amount $\left(\sim 31 \mathrm{mmol} \cdot \mathrm{kg}^{-1}\right)$ of sulfate groups on the surface of the CNWs, which cause 


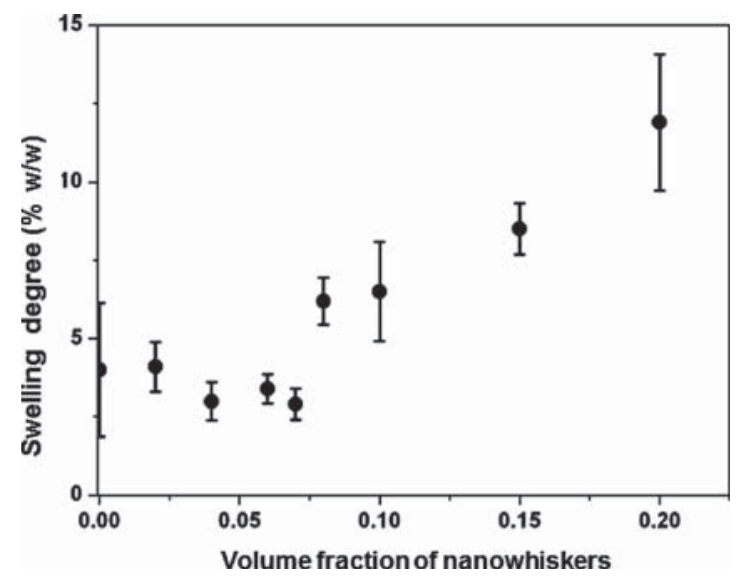

Figure 3. Aqueous swelling of polyurethane/cellulose nanowhisker nanocomposites as a function of nanowhisker volume fraction. Swelling was determined after 5 days of immersion in deionized water at $37^{\circ} \mathrm{C}$. Data points represent averages $(N=3-9) \pm$ standard deviation.

electrostatic repulsion between the nanowhiskers and lead to their good dispersibility in many polar solvents. ${ }^{34}$ Nanocomposite films composed of 0 to $20 \% \mathrm{v} / \mathrm{v}$ CNWs in PU were produced by solutioncasting mixtures of these components from DMF and subsequent compression molding (see Experimental Section for details). The specific PU, based on poly(tetramethylene glycol), butanediol, and $4,4^{\prime}$-methylenebis(phenyl isocyanate), was chosen due to its combination of modest water take-up (vide infra) and low modulus.

Aqueous Swelling. Before exploring the chemo-responsive behavior, i.e., changes of the mechanical properties of the PU/ CNW nanocomposites upon exposure to water, we studied their swelling behavior in this medium. After immersing the PU/ CNW nanocomposites to saturation (5 days) in deionized water at $37{ }^{\circ} \mathrm{C}$, i.e., a temperature that is of particular interest for biomedical applications, the degree of swelling was determined gravimetrically (Figure 3 ). The uptake of water increased gradually with the whisker content from $4 \% \mathrm{w} / \mathrm{w}$ for the neat PU to $12 \% \mathrm{w} / \mathrm{w}$ for the nanocomposite containing $20 \% \mathrm{v} / \mathrm{v}$ CNWs. This effect can be attributed to the increased hydrophilicity of the nanocomposite on account of the presence of cellulose nanowhiskers. The level of water take-up is very modest and much more moderate than observed in comparable nanocomposites comprising tunicate nanowhiskers (up to $70 \% \mathrm{w} / \mathrm{w}$ ). This finding mirrors our recent data for poly(vinylacetate)/CNW nanocomposites, which swell less than the corresponding nanocomposites with tunicate nanowhiskers, and is explained by the lower sulfate charge density of the cotton nanowhiskers. ${ }^{33}$ There may also be more accessible paracrystalline material in the cotton cellulose nanowhiskers compared to tunicate cellulose nanowhiskers. It is interesting to note that the water uptake of PU/ CNW nanocomposites seems to trace the tensile modulus (cf. Figure 4); i.e., the water uptake is constant at a level of about $3-5 \% \mathrm{w} / \mathrm{w}$ up to the percolation threshold, beyond which it increases in a relatively linear fashion. This is consistent with the interpretation that the percolating $\mathrm{CNW}$ network is the major driving force and pathway for water absorption and transport, respectively. The overall very modest water uptake bodes well for possible applications, where excessive swelling is undesirable.

Adaptive Mechanical Properties. The thermo-mechanical properties of the nanocomposites films obtained by casting and compression molding were established by dynamic mechanical

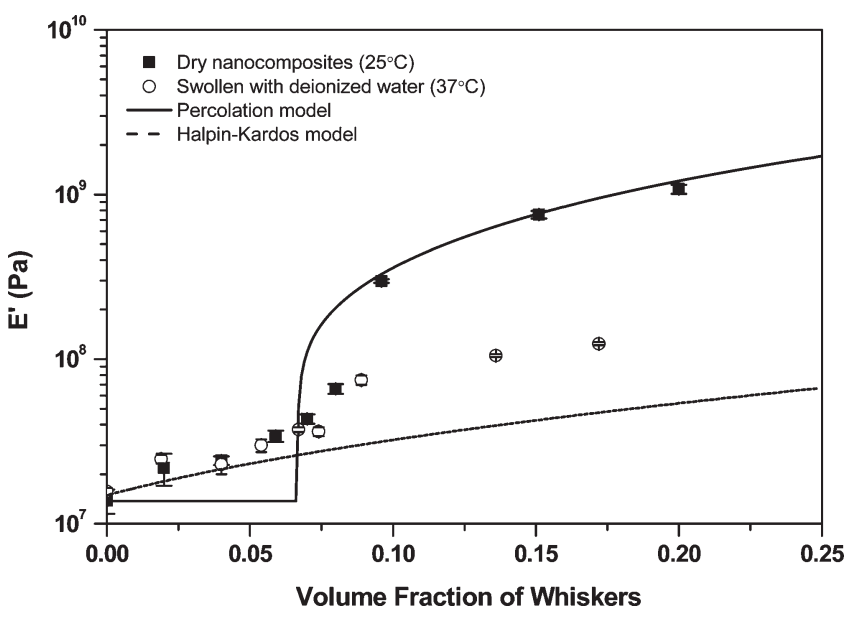

Figure 4. Tensile storage moduli $E^{\prime}$ of neat polyurethane and polyurethane/cellulose nanowhisker nanocomposites as a function of volume fraction of cellulose nanowhiskers in the dry state at $25^{\circ} \mathrm{C}$ and water-swollen state (after immersion in deionized water at $37^{\circ} \mathrm{C}$ for 5 days). Data points represent averages $(N=3-7) \pm$ standard deviation. Lines represent values predicted by the percolation (solid) and HalpinKardos (dashed) models.

thermal analysis (DMTA) as a function of composition. Figure 4 shows the tensile storage moduli $\left(E^{\prime}\right)$ at $25^{\circ} \mathrm{C}$, for both dry and water-swollen films (after swelling with deionized water at $37{ }^{\circ} \mathrm{C}$ ). The data were fitted using percolation and HalpinKardos models, using a CNW aspect ratio of 10.5, a whiskerphase tensile storage modulus of $13.0 \mathrm{GPa}$, a Poisson's ratio of 0.3 and a matrix tensile storage modulus of $13.8 \mathrm{MPa}$ for the percolation model and transverse and longitudinal tensile moduli of 5 and $130 \mathrm{GPa}$ for the Halpin-Kardos model. Details about these models are provided elsewhere. ${ }^{32,34,35,47,49}$ At $25^{\circ} \mathrm{C}$ the neat, dry PU has a storage modulus of $14 \mathrm{MPa}$, which increases upon incorporation of the CNWs. For the nanocomposite with the highest CNW content investigated $(20 \% \mathrm{v} / \mathrm{v})$ an $E^{\prime}$ of 1076 $\mathrm{MPa}$ was measured, which represents a stiffness increase of almost 2 orders of magnitude. The significant reinforcement, evident from the large value of the whisker-phase tensile storage modulus of $13.0 \mathrm{GPa}$ (obtained as a result from a least-squares fit of the percolation model against the data) suggests that interfacial interactions (hydrogen bonding) between the polyurethane and CNWs may contribute to the increase of $E^{\prime}$, as suggested previously by Berglund et al. ${ }^{58}$ Figure 4 shows that the magnitude of the reinforcement follows the Halpin-Kardos model for CNW contents below the percolation threshold (ca. $7 \% \mathrm{v} / \mathrm{v}$ ) and the percolation model for CNW contents above this limit. The agreement with the percolation model is indicative of the formation of a percolating CNW network within the rubbery matrix and strong interactions between the nanowhiskers via hydrogen bonding. ${ }^{36}$

Figure 4 also shows the tensile storage moduli $E^{\prime}$ of the neat $\mathrm{PU}$ and PU/CNW nano films that had been immersed in deionized water for 5 days (i.e., to equilibrium) at $37^{\circ} \mathrm{C}$, before being tested in a DMTA setup that allowed the samples to be immersed in deionized water during the tests. The experiments were conducted in a temperature regime of $25-50{ }^{\circ} \mathrm{C}$; with the notion that the temperature influence is small, and with biomedical applications in mind, results are quoted here for a temperature of $37^{\circ} \mathrm{C}$. As can be seen from Figure 4 and Table 1, the 
Table 1. Modulus and Swelling of PU and PU/CNW Nanocomposite Films ${ }^{a}$

\begin{tabular}{|c|c|c|c|c|c|c|}
\hline \multicolumn{2}{|c|}{$\operatorname{dry}\left(25^{\circ} \mathrm{C}\right)$} & \multicolumn{2}{|c|}{ wet $\left(25^{\circ} \mathrm{C}\right)$} & \multicolumn{2}{|c|}{ wet $\left(37^{\circ} \mathrm{C}\right)$} & \multirow[b]{2}{*}{$\begin{array}{c}\text { swelling } \\
\text { (\%) }\end{array}$} \\
\hline $\begin{array}{c}\mathrm{CNW} \\
\text { content } \\
(\% \mathrm{v} / \mathrm{v})\end{array}$ & $\begin{array}{c}\text { av } E^{\prime} \\
(\mathrm{MPa})\end{array}$ & $\begin{array}{l}\text { CNW } \\
\text { content } \\
(\% \mathrm{v} / \mathrm{v})\end{array}$ & $\begin{array}{c}E^{\prime} \\
(\mathrm{MPa})\end{array}$ & $\begin{array}{c}\text { CNW } \\
\text { content } \\
(\% \mathrm{v} / \mathrm{v})\end{array}$ & $\begin{array}{c}E^{\prime} \\
(\mathrm{MPa})\end{array}$ & \\
\hline 0.0 & 14 & 0.0 & 16 & 0.0 & 16 & 4.0 \\
\hline 2.0 & 22 & 1.9 & 26 & 1.9 & 25 & 4.1 \\
\hline 4.0 & 24 & - & - & 4.0 & 21 & 3.0 \\
\hline 5.9 & 34 & 5.5 & 32 & 5.4 & 30 & 3.4 \\
\hline 7.0 & 43 & - & - & 6.7 & 45 & 2.9 \\
\hline 8.0 & 66 & 7.5 & 40 & 7.4 & 36 & 6.2 \\
\hline 9.6 & 298 & 9.0 & 86 & 8.9 & 75 & 6.5 \\
\hline 15.1 & 755 & 13.7 & 122 & 13.6 & 105 & 8.5 \\
\hline 20.0 & 1076 & 17.5 & 144 & 17.2 & 124 & 11.9 \\
\hline
\end{tabular}

${ }^{a}$ Data quoted are averages of $N=5$ independent measurements. stiffness of samples comprising more than $4 \% \mathrm{v} / \mathrm{v}$ CNWs was reduced upon aqueous swelling. For example, $E^{\prime}$ of the material comprising a CNW content of $20 \% \mathrm{v} / \mathrm{v}$ decreased by almost an order of magnitude from 1076 to $124 \mathrm{MPa}$. By contrast, no appreciable mechanical contrast was seen for samples comprising CNWs at a concentration below the percolation threshold. This is consistent with the proposed model for mechanical switching in the present materials. Water 'switches off' the CNW-CNW interactions through competitive hydrogen bonding. The fact that the "off" values are somewhat higher than predicted by the Halpin-Kardos model is explained with the relatively moderate amount of water take-up, which may prevent complete switching. Of particular interest in the context of the shape-memory effect discussed later are compositions with a high CNW content, for which the largest absolute contrasts are seen.

To develop an understanding of the dynamics of the softening and stiffening of the nanocomposites upon immersion and drying, the mechanical properties were measured via DMTA under isothermal conditions as a function of time, using again a

a)

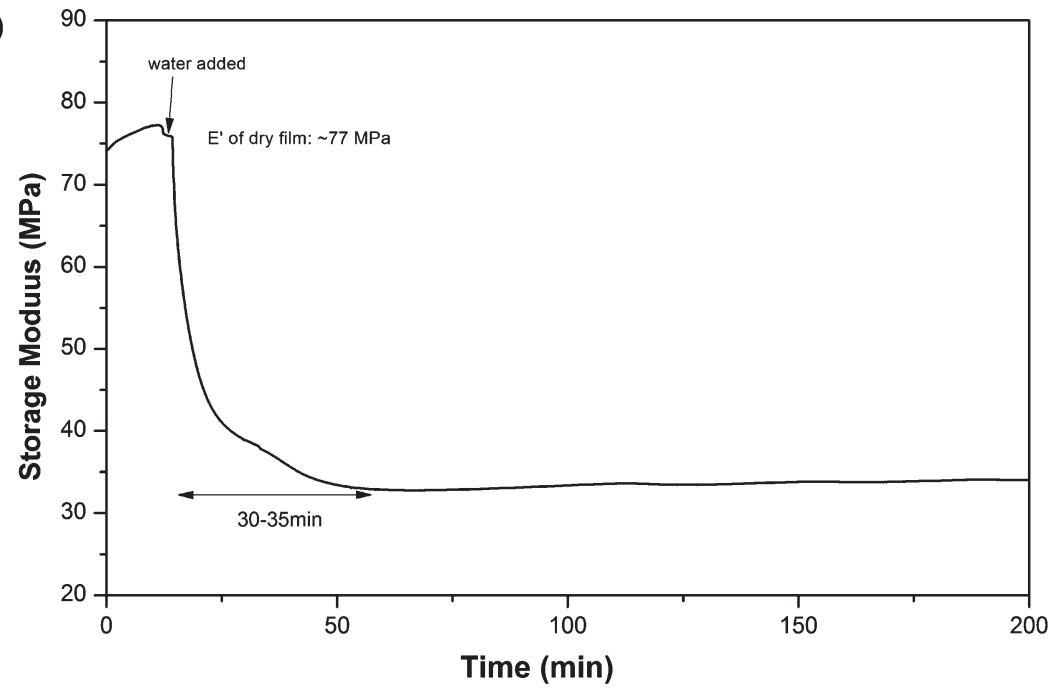

b)

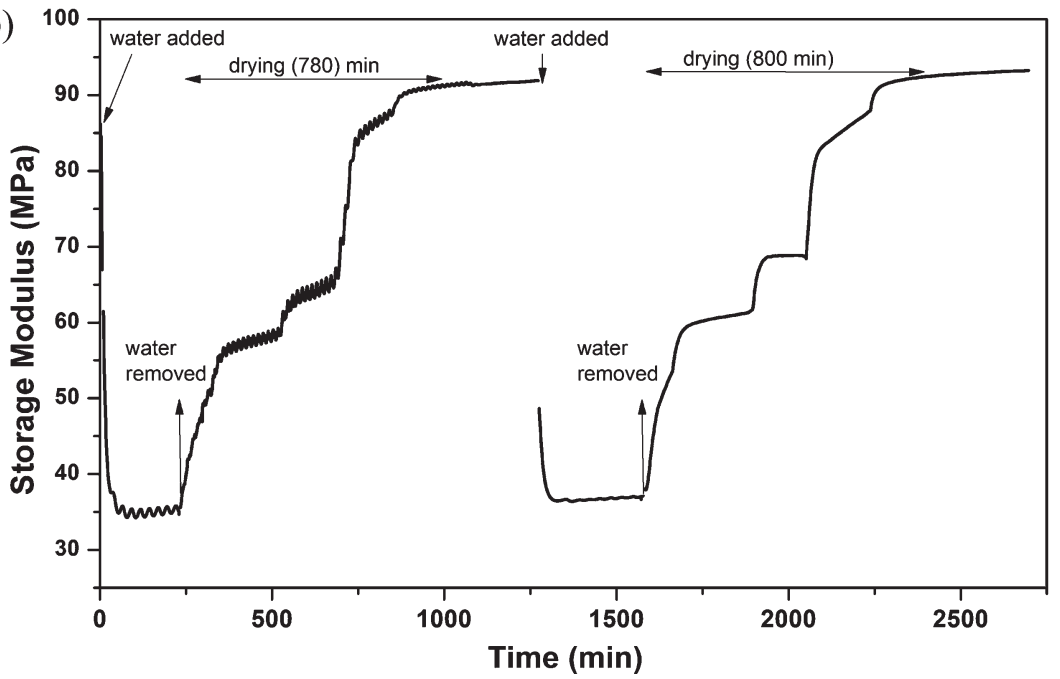

Figure 5. Storage modulus $E^{\prime}$ of $300 \mu \mathrm{m}$ thin polyurethane/cellulose nanowhisker nanocomposite films comprising $7.5 \% \mathrm{v} / \mathrm{v}$ nanowhiskers as a function of time and exposure/removal of water. (a) Storage modulus $E^{\prime}$ as a function of time upon wetting a sample at $35 \pm 2{ }^{\circ} \mathrm{C}$. (b) As in part a, but showing subsequent drying, wetting, and drying cycles at $35 \pm 2{ }^{\circ} \mathrm{C}$. Samples were dried in the DMTA instrument after removal of water. 
a)
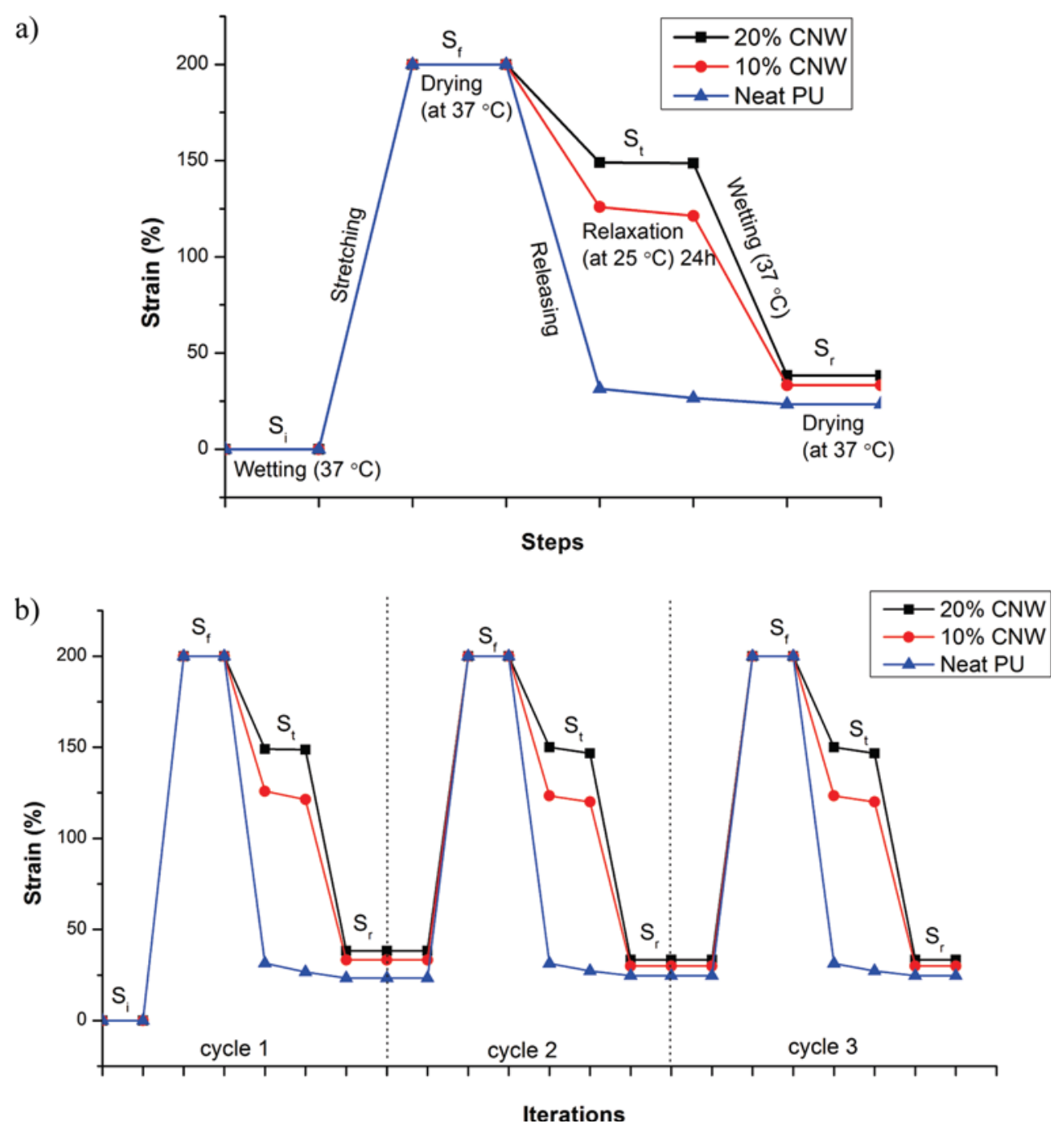

Figure 6. Strain as a function of (a) steps and (b) iterations of shape-memory experiments conducted with polyurethane/cellulose nanowhisker nanocomposite films comprising $0,10,20 \% \mathrm{v} / \mathrm{v}$ cotton nanowhiskers, where $S_{\mathrm{i}}$ is the initial shape with length $l_{\mathrm{i}}, S_{\mathrm{f}}$ is the intermediate shape under stress with length $l_{\mathrm{f}}, S_{\mathrm{t}}$ is the temporary shape (stress-free) with length $l_{\mathrm{t}}$, and $S_{\mathrm{r}}$ is the recovered shape with length $l_{\mathrm{r}}$.

setup that allowed us to keep the samples immersed in deionized water during the tests. It is noted, that these results are of course strongly influenced by the dimensions of the samples, and the drying conditions and perhaps the composition. Figure 5a shows $E^{\prime}$ of the PU/CNW nanocomposite with $7.5 \% \mathrm{v} / \mathrm{v} \mathrm{CNWs}$ at a temperature of $35{ }^{\circ} \mathrm{C}$ as a function of immersion time. An exponential decrease of $E^{\prime}$ can be observed after addition of water and within about $30 \mathrm{~min}$, the stiffness has stabilized at a level that corresponds to the wet state. It should be noted that the kinetics are related to the film thickness (here $200-300 \mu \mathrm{m}$ ), since the switching process involves diffusion of water through the material. After removal of water (Figure $5 b$ ), $E^{\prime}$ increased steadily to regain the original stiffness, although this process was much slower than the wetting, lasting about $13 \mathrm{~h}$. The drying process is nonlinear, in that several "steps" can be clearly discerned. Repeated wetting/drying showed that the steps are reproducible, and reference experiments with neat PU reference films. showed similar, although less pronounced features. However,their origin is, at this stage, unclear.

Shape-Memory Effect. To explore the stimuli-responsive shape-memory behavior of the new PU/CNW nanocomposites,
Table 2. Shape Fixing and Recovery Ability of Cotton Cellulose Whiskers Filled PU Nanocomposites

\begin{tabular}{lcc}
\multicolumn{1}{c}{ sample } & shape fixing $\left(R_{f}\right)(\%)$ & shape recovery $\left(R_{r}\right)(\%)$ \\
neat PU & 13.3 & 1.6 \\
PU/CNW, 10\% & 60.7 & 44 \\
PU/CNW, 20\% & 74.3 & 55.2 \\
\hline
\end{tabular}

thin films were wetted with water, deformed by application of uniaxial stress from their original shape $S_{\mathrm{i}}$ to a maximum strain $\left(l_{\mathrm{f}}-l_{\mathrm{i}}\right) / l_{\mathrm{i}}$ of $200 \%\left(\right.$ shape $\left.S_{\mathrm{f}}\right)$ and dried under fixed stress. After drying, the stress was released, and the samples contracted to a temporary shape $S_{\mathrm{t}}$. The samples were subsequently immersed in deionized water, which caused relaxation to a recovered shape $S_{r}$. Figure 6 shows this cycle for the neat PU and PU/CNW nanocomposites comprising 10 and $20 \% \mathrm{v} / \mathrm{v}$ CNWs, respectively. Table 2 represents the relevant figures of merit in terms of shape fixing $\left(R_{\mathrm{f}}\right)$ and shape recovery $\left(R_{\mathrm{r}}\right)$.

As can be seen from Figure 6a, the neat polyurethane films contract significantly upon stress removal and only a marginal 


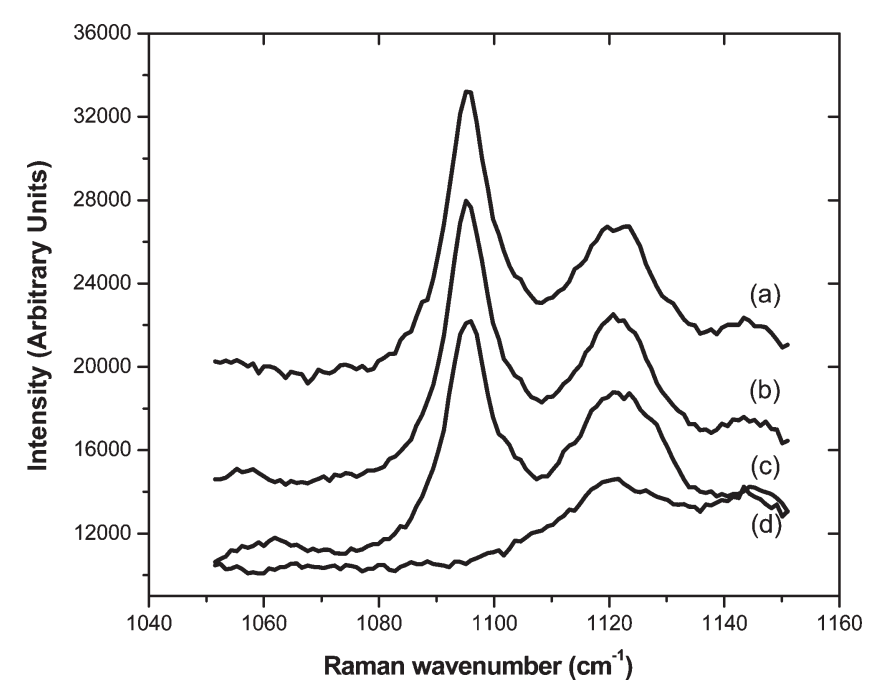

Figure 7. Raman spectra of films of polyurethane/cellulose nanowhisker nanocomposites comprising $20 \% \mathrm{v} / \mathrm{v}$ cotton nanowhiskers after (a) stretching to $70 \%$ strain (wet) and recovering to $65 \%$ and (b) stretching to $70 \%$ (wet) and recovering to $50 \%$ and for (c) undeformed polyurethane/cellulose nanocomposite and (d) pure polyurethane.

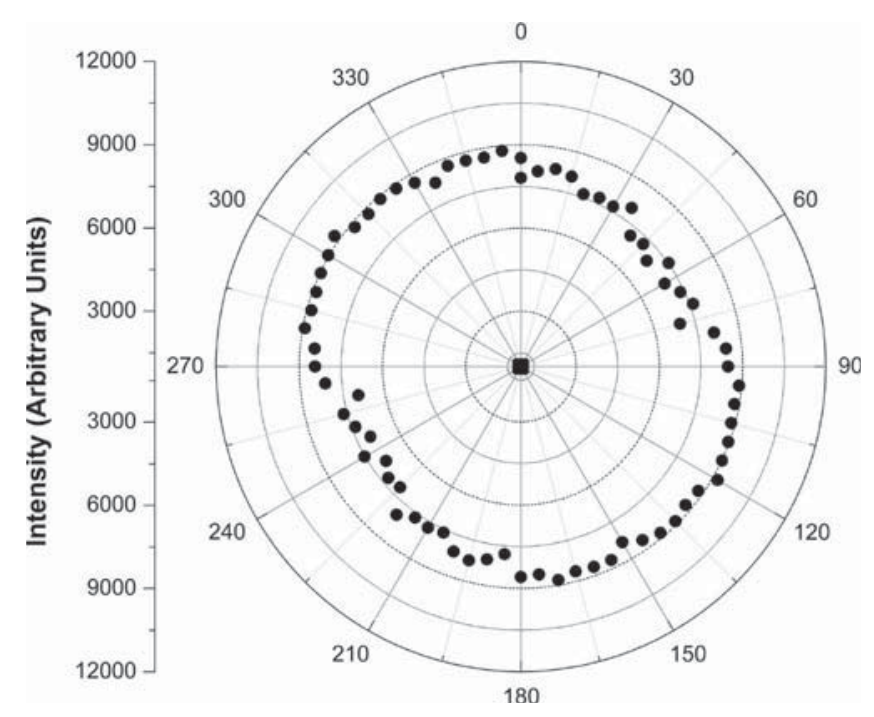

Figure 8. Polar plots of the intensity of the Raman band located at $1095 \mathrm{~cm}^{-1}$ as a function of rotation angle of an undeformed polyurethane/cellulose nanowhisker nanocomposite film comprising $20 \% \mathrm{v} / \mathrm{v}$ cotton nanowhiskers.

shape-memory effect is seen upon exposure to water with $R_{f}=13.3 \%$ and $R_{r}=1.6 \%$ (Table 2). Relaxation is not complete, i.e., the neat PU films do not completely recover to their original shape, but rather retain a strain of $23 \%$. This phenomenon is wellknown and related to irreversible morphological changes that involve orientation of the hard segments. ${ }^{59,60}$ Therefore, cyclic experiments based on PUs normally include an initial 'conditioning' cycle, which serves to "pre-stretch" the PU before comparative, cyclic experiments are also carried out and eliminates the otherwise appreciable hysteresis between the first and second step (Figure $6 \mathrm{~b}$ ). The shape fixing value $\left(R_{\mathrm{f}}\right)$ of neat PU also indicates that the basic ability of fixing the temporary shape can originate from the orientation of hard segments of PU chains. (a)

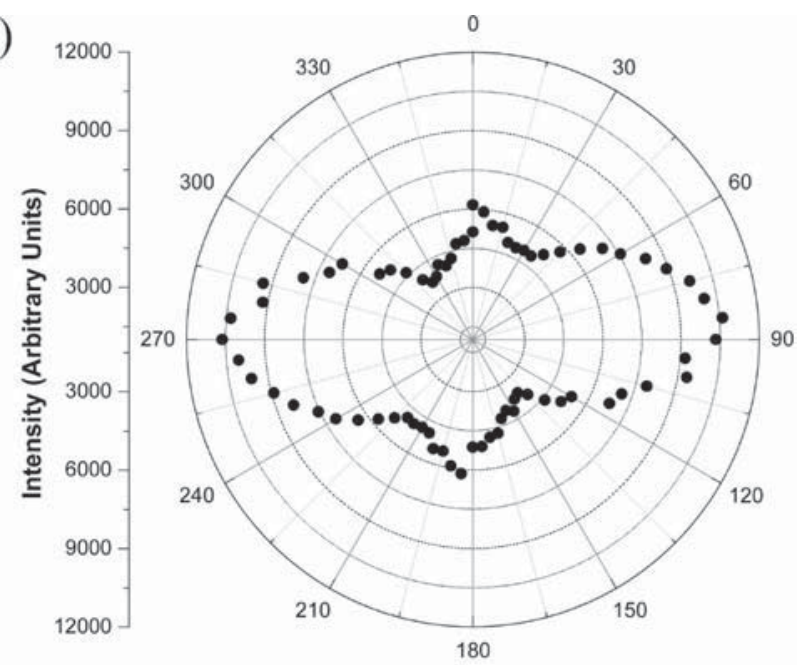

(b)

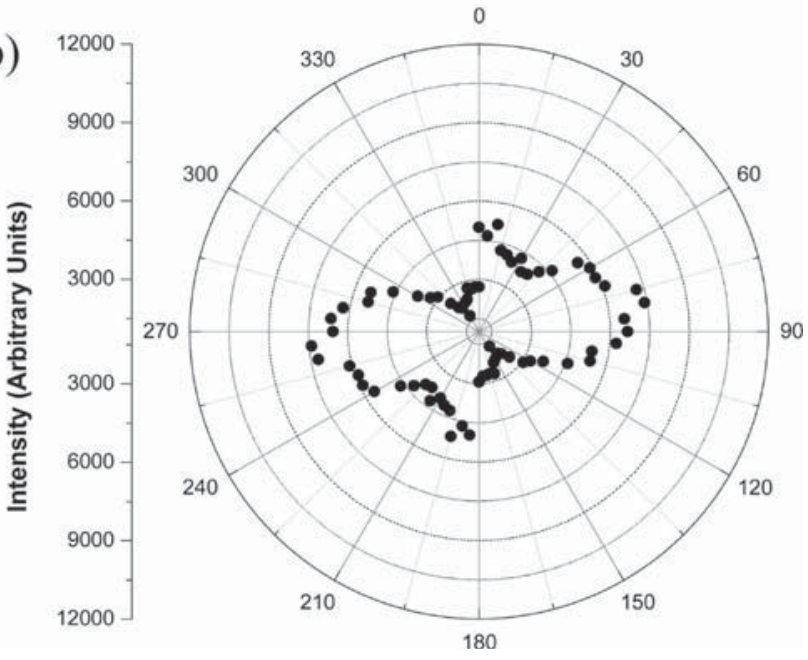

Figure 9. Polar plots of the intensity of the Raman band located at $1095 \mathrm{~cm}^{-1}$ as a function of rotation angle of polyurethane/cellulose nanowhisker nanocomposite films comprising $20 \% \mathrm{v} / \mathrm{v}$ cotton nanowhiskers that were wetted, stretched to a strain of (a) $70 \%$ and (b) $70 \%$ for $5 \mathrm{~min}$ and recovered (wet) after $5 \mathrm{~min}$ to strains of $65 \%$ and $50 \%$ for parts $a$ and $b$, respectively.

Water-swollen nanocomposites with 10 or $20 \% \mathrm{v} / \mathrm{v}$ CNW can readily be deformed to strains of $200 \%$, and retain a strain of 125 and $149 \%$, respectively, upon drying and stress removal (Figure 6a). Thus, shape fixing $\left(R_{f}\right)$ values $(60.7$ and $74.3 \%$ for nanocomposites with 10 and $20 \%$ CNWs, respectively), are considerably higher than for the neat PU (13.3\%). Under dry conditions (relative humidity $<45 \%$ ), this temporary shape $\left(S_{t}\right)$ is retained for $>24 \mathrm{~h}$, indicating the formation of a moderately aligned cellulose nanowhiskers network upon drying, which fixates the temporary shape $S_{t}$ (Figure 1). As a consequence of the formation of a network of interacting rigid nanowhiskers the ability to fix this temporary shape $\left(R_{f}\right.$, Table 2$)$ increases with increasing CNW content. When again immersed in deionized water, these films contract and relax to a shape $S_{r}$, which shows only a slightly higher residual elongation (strains of 33 and $38 \%$ for 10 and $20 \% \mathrm{v} / \mathrm{v} \mathrm{CNW}$ ) than the neat PU reference film $($ strain $=23 \%)$. Consequently, the shape recovery (44 and $55.2 \%$ for nanocomposites with 10 and $20 \% \mathrm{CNWs}$, respectively), is considerably higher than that of the neat PU (1.6\%). 


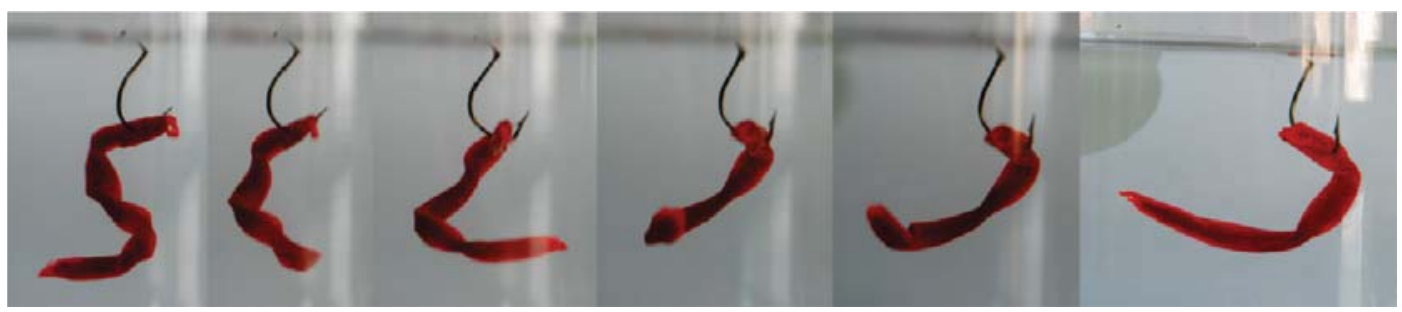

Figure 10. Water-induced shape-memory effect used in an artificial, self-propelled fishing lure.

Thus, switching interactions between percolating, rigid nanofibers in a polymer matrix "on" and "off" not only allows one to create stimuli-responsive nanocomposites, but the effect allows, if an elastic matrix is employed, to create shape-memory materials. In order to quantify to what extent the hysteresis, which reduces the shape recovery, is related to the irreversible behavior of the matrix, we conducted cyclic shape-memory experiments, which are shown in Figure 6b. Gratifyingly, it can be seen that the hysteresis vanishes after the first cycle.

Probing the Mechanism. To better understand the role of the cellulose nanowhiskers in the PU nanocomposites with respect to the shape-memory recovery process and to probe the underlying mechanism, investigations were extended to Raman spectral analysis. The orientation of the nanowhiskers was analyzed based on a change of the intensity of the $\mathrm{C}-\mathrm{O}$ ring stretch mode located at $1095 \mathrm{~cm}^{-1}$ (Figure 7). This orientation measurement involves recording intensity changes of this band as a function of the orientation of the specimen relative to the polarization axis. ${ }^{61}$ The intensity of the Raman band located at $1095 \mathrm{~cm}^{-1}$ is maximal if the cellulose chains, and therewith the CNWs, are oriented parallel to the polarization direction. Consequently, the presence of oriented CNWs results in a marked change in the intensity of this band when the axis of the whiskers is rotated away from this condition.

Raman spectra of films of the neat polyurethane and nanocomposites comprising $20 \% \mathrm{v} / \mathrm{v}$ CNWs before and after wetting, uniaxial deformation, and drying the samples to obtain a temporary shape $S_{t}$ are shown in Figure 7, with the axis of the samples oriented parallel to the polarization axis. All spectra show a high intensity Raman band located at $1095 \mathrm{~cm}^{-1}$ that is due to the $\mathrm{C}-\mathrm{O}$ ring stretch mode of the nanowhiskers. A polar scan, which plots the intensity of this band as a function of rotation angle, shows that in nanocomposite films that were neither wetted nor stretched, no preferential orientation of the CNWs exists, since the intensity does not change with rotation angle (Figure 8 ). The picture is different for nanocomposite films that were deformed to temporary shapes $S_{t}$ with residual strains of between $50 \%$ and $65 \%$ (Figure 9). In all stretched samples, the CNWs are aligned parallel to both the stretching and polarization axes. Thus, the data show nicely that the level of orientation depends on the extent of uniaxial deformation. The polar scan of a highly stretched sample (residual strain $=65 \%$, Figure 9a) shows almost uniaxial orientation of the CNWs, whereas the data of a less oriented sample (residual strain $=50 \%$ Figure $9 \mathrm{~b}$ ) reflect some biaxial orientation. Overall the data show that in the stress-free temporary shape $S_{t}$ the CNWs display a higher level of uniaxial orientation than in the initial shape $S_{i}$. This is consistent with the interpretation that upon drying the water-swollen, deformed nanocomposite samples, hydrogen bonds are established between oriented CNWs that may be attributable for stabilizing the temporary shape $\left(S_{t}\right)$ by re-establishing a percolating, oriented network. It is apparent that incorporating CNWs at levels which can form percolating networks plays a key role not only in improving and switching the mechanical properties, but also in determining the temporary shape and water-induced shapememory recovery effect. It appears that the approach used to create the water-induced shape recovery effect displayed by the materials studied here is general and may be exploitable in different types of mechanically adaptive materials.

Demonstrative Object. The new shape-memory effect introduced here may be useful for certain biomedical applications, where slow, water-diffusion driven mechanical changes and not fast, thermally activated adaptability are desired. The effect may also be useful for consumer applications, for example, self-propelled, artificial fishing lures. Figure 10 shows the momentary shapes of an artificial worm, which twists when wetted and may attract fish in a different manner than static artificial lures. The specimen was fabricated from a PU/ CNW nanocomposite comprising $10 \% \mathrm{v} / \mathrm{v}$ of $\mathrm{CNW}$, by twisting the swollen specimen and drying in the twisted state. During recovery in deionized water, from the shape $S_{t}$ to shape $S_{r}$, it can be seen that quickly after immersion into water, the specimen moves autonomously, returning slowly to its original shape.

\section{CONCLUSIONS}

We demonstrated that the incorporation of cellulose nanowhiskers, at a concentration around or above the percolation limit, in an elastomeric polyurethane matrix can result in stimuli-responsive nanocomposites, which exhibit mechanically adaptive properties as well as shape-memory behavior. The aqueous swelling behavior of such nanocomposites was observed to increase in a nonlinear fashion with increasing nanowhisker content, suggesting that the water uptake is enhanced by the hydrophilic cellulose and the formation of a nanowhisker network above the percolation limit. Competitive hydrogen bonding of water molecules with the surface hydroxyl groups of the cellulose nanowhiskers changes the hydrogen bonding between the nanowhiskers upon wetting/swelling, and causes a significant reduction of the material's tensile storage modulus. This effect is fully reversible. In the water-swollen, softened state, tensile deformation of the nanocomposites causes a significant level of uniaxial orientation of the cellulose nanowhiskers, which is retained upon drying the materials. The resulting oriented network serves to efficiently fixate a temporary shape, which upon wetting relaxes again to the original shape, due to the elastic polymer matrix employed. It appears that the approach used to create the water-induced shape recovery effect displayed by the materials studied here is general and may be exploitable in different types of mechanically adaptive materials.

\section{AUTHOR INFORMATION}

\section{Present Addresses}

${ }^{\perp}$ Forestry Research Institute Malaysia (FRIM), 52110 Kepong, Selangor Darul Ehsan, Kuala Lumpur, Malaysia. 
\#Department of Engineering, McNeese State University, 4205 Ryan Street, Lake Charles, LA 70609, United States.

\section{ACKNOWLEDGMENT}

The authors gratefully acknowledge financial support received from the Swiss National Science Foundation (NRP 62: Smart Materials, Nr. 406240 126046), the Adolphe Merkle Foundation, and the National Science Foundation (USA) under Grant No. CBET-0828155. R.R. wishes to thank the Malaysian Government for a doctoral scholarship.

\section{REFERENCES}

(1) Liu, C.; Qin, H.; Mather, P. T. J Mater Chem 2007, 17, 1543.

(2) Lendlein, A.; Langer, R. Science 2002, 296, 1673.

(3) Lendlein, A.; Kelch, S. Angew. Chem. Int. Ed. 2002, 41, 2034.

(4) Wei, Z. G.; Sandstrom, R.; Miyazaki, S. J. Mater. Sci. 1998, 33, 3743.

(5) Lendlein, A.; Jiang, H. Y.; Junger, O.; Langer, R. Nature 2005, 434, 879.

(6) Jiang, H. Y.; Kelch, S.; Lendlein, A. Adv. Mater. 2006, 18, 1471.

(7) Lee, K. M.; Koerner, H.; Vaia, R. A.; Bunning, T. J.; White, T. J. Soft Matter 2011, 7, 4318.

(8) Mohr, R.; Kratz, K.; Weigel, T.; Lucka-Gabor, M.; Moneke, M.; Lendlein, A. Proc. Natl. Acad. Sci. U.S.A. 2006, 103, 3540.

(9) Schmidt, A. M. Macromol. Rapid Commun. 2006, 27, 1168.

(10) Huang, W. M.; Yang, B.; An, L.; Li, C.; Chan, Y. S. Appl. Phys. Lett. 2005, 86.

(11) Huang, W. M.; Yang, B.; Zhao, Y.; Ding, Z. J. Mater. Chem. 2010, 20, 3367.

(12) Lv, H. B.; Leng, J. S.; Liu, Y. J.; Du, S. Y. Adv. Eng. Mater. 2008, 10,592 .

(13) Du, H. Y.; Zhang, J. H. Soft Matter 2010, 6, 3370.

(14) El Feninat, F.; Laroche, G.; Fiset, M.; Mantovani, D. Adv. Eng. Mater. 2002, 4, 91.

(15) Sokolowski, W.; Metcalfe, A.; Hayashi, S.; Yahia, L.; Raymond, J. Biomed. Mater. 2007, 2, S23.

(16) Yakacki, C. M.; Shandas, R.; Safranski, D.; Ortega, A. M.; Sassaman, K.; Gall, K. Adv. Funct. Mater. 2008, 18, 2428.

(17) Small, W.; Singhal, P.; Wilson, T. S.; Maitland, D. J. J. Mater. Chem. 2010, 20, 3356.

(18) Behl, M.; Razzaq, M. Y.; Lendlein, A. Adv. Mater. 2010, 22, 3388 .

(19) Meng, Q. H.; Hu, J. L. Compos. Part A: Appl. S 2009, 40, 1661.

(20) Xie, T.; Xiao, X. C. Chem. Mater. 2008, 20, 2866.

(21) Kunzelman, J.; Chung, T.; Mather, P. T.; Weder, C. J. Mater. Chem. 2008, 18, 1082.

(22) Flory, P. J.; Rehner, J. J. Chem. Phys. 1943, 11, 512.

(23) Bellin, I.; Kelch, S.; Langer, R.; Lendlein, A. Proc. Natl. Acad. Sci. U.S.A. 2006, 103, 18043.

(24) Behl, M.; Bellin, I.; Kelch, S.; Wagermaier, W.; Lendlein, A. Adv. Funct. Mater. 2009, 19, 102.

(25) Xie, T. Nature 2010, 464, 267

(26) Xie, T.; Xiao, X. C.; Cheng, Y. T. Macromol. Rapid Commun. 2009, 30, 1823.

(27) Cuevas, J. M.; Alonso, J.; German, L.; Iturrondobeitia, M.; Laza, J. M.; Vilas, J. L.; Leon, L. M. Smart Mater Struct 2009, 18.

(28) Maitland, D. J.; Metzger, M. F.; Schumann, D.; Lee, A.; Wilson, T. S. Laser Surg. Med. 2002, 30, 1.

(29) Koerner, H.; Price, G.; Pearce, N. A.; Alexander, M.; Vaia, R. A. Nat. Mater. 2004, 3, 115.

(30) Liu, Y. J.; Lv, H. B.; Lan, X.; Leng, J. S.; Du, S. Y. Compos. Sci. Technol. 2009, 69, 2064.

(31) Yang, B.; Huang, W. M.; Li, C.; Chor, J. H. Eur. Polym. J. 2005, $41,1123$.
(32) Capadona, J. R.; Shanmuganathan, K.; Tyler, D. J.; Rowan, S. J.; Weder, C. Science 2008, 319, 1370.

(33) Rusli, R.; Shanmuganathan, K.; Rowan, S. J.; Weder, C.; Eichhorn, S. J. Biomacromolecules 2010, 11, 762 .

(34) Shanmuganathan, K.; Capadona, J. R.; Rowan, S. J.; Weder, C. J. Mater. Chem. 2010, 20, 180.

(35) Shanmuganathan, K.; Capadona, J. R.; Rowan, S. J.; Weder, C. Prog. Polym. Sci. 2010, 35, 212.

(36) Shanmuganathan, K.; Capadona, J. R.; Rowan, S. J.; Weder, C. ACS Appl. Mater. Inter. 2010, 2, 165.

(37) Hsu, L.; Weder, C.; Rowan, S. J. J. Mater. Chem. 2011, 21, 2812.

(38) Hess, A. E.; Capadona, J. R.; Shanmuganathan, K.; Hsu, L.; Rowan, S. J.; Weder, C.; Tyler, D. J.; Zorman, C. A. J. Micromech. Microeng. 2011, 21, No. 054009.

(39) Harris, J. H.; Hess, A.; Rowan, S.; Weder, C.; Zorman, C. A.; Tyler, D. J.; Capadona, J. R. J. Neural Eng. 2011, 8, 046010.

(40) Szulgit, G. K.; Shadwick, R. E. J. Exptl. Biol. 2000, 203, 1539.

(41) Trotter, J. A.; Tipper, J.; Lyons-Levy, G.; Chino, K.; Heuer, A. H.; Liu, Z.; Mrksich, M.; Hodneland, C.; Dillmore, W. S.; Koob, T. J.; Koob-Emunds, M. M.; Kadler, K.; Holmes, D. Biochem. Soc. Trans. 2000, 28,357 .

(42) Lima, M. M. D.; Borsali, R. Macromol. Rapid Commun. 2004, 25,771 .

(43) Habibi, Y.; Lucia, L. A.; Rojas, O. J. Chem Rev 2010, 110, 3479.

(44) Eichhorn, S. J.; Dufresne, A.; Aranguren, M.; Marcovich, N. E.; Capadona, J. R.; Rowan, S. J.; Weder, C.; Thielemans, W.; Roman, M.; Renneckar, S.; Gindl, W.; Veigel, S.; Keckes, J.; Yano, H.; Abe, K.; Nogi, M.; Nakagaito, A. N.; Mangalam, A.; Simonsen, J.; Benight, A. S.; Bismarck, A.; Berglund, L. A.; Peijs, T. J. Mater. Sci. 2010, 45, 1.

(45) Eichhorn, S. J. Soft Matter 2011, 7, 303.

(46) Tang, L. M.; Weder, C. ACS Appl. Mater. Inter. 2010, 2, 1073.

(47) Capadona, J. R.; Van Den Berg, O.; Capadona, L. A.; Schroeter,

M.; Rowan, S. J.; Tyler, D. J.; Weder, C. Nat. Nanotechnol. 2007, 2, 765.

(48) van den Berg, O.; Schroeter, M.; Capadona, J. R.; Weder, C. J. Mater. Chem. 2007, 17, 2746.

(49) Capadona, J. R.; Shanmuganathan, K.; Triftschuh, S.; Seidel, S.; Rowan, S. J.; Weder, C. Biomacromolecules 2009, 10, 712.

(50) Cao, X. D.; Dong, H.; Li, C. M. Biomacromolecules 2007, 8, 899.

(51) Seydibeyoglu, M. O.; Oksman, K. Compos. Sci. Technol. 2008, 68,908 .

(52) Wu, Q. J.; Henriksson, M.; Liu, X.; Berglund, L. A. Biomacromolecules 2007, 8, 3687.

(53) Pei, A. M., J. M.; Ruokolainen, J.; Zhou, Q.; Berglund, L. A. Macromolecules 2011, 44 (11), 4422.

(54) Dong, X. M.; Kimura, T.; Revol, J. F.; Gray, D. G. Langmuir 1996, 12, 2076.

(55) Perez, D. D.; Montanari, S.; Vignon, M. R. Biomacromolecules 2003, 4, 1417.

(56) Wiley, J. H.; Atalla, R. H. Carbohydr. Res. 1987, 160, 113.

(57) Marquardt, D. W. J. Soc. Ind. Appl. Math. 1963, 11, 431.

(58) Wu, Q.; Henriksson, M.; Liu, X.; Berglund, L. A. Biomacromolecules 2007, 8, 3687.

(59) Christenson, E. M.; Anderson, J. M.; Hiltner, A.; Baer, E. Polymer 2005, 46, 11744.

(60) Crenshaw, B. R.; Weder, C. Macromolecules 2006, 39, 9581.

(61) Rusli, R,; Eichhorn, S. J. Appl. Phys. Lett. 2008, 93, 033111. 